\title{
A Systematic Review of the Literature on the Relationship between Caste Membership and Health-Related Risk Factors in India
}

\author{
Ken Russell Coelho, Catherine Belden
}

\section{Ken Russell Coelho, Catherine Belden}

College of Graduate Health Studies, A.T. Still University, 5850 E Still Cir, Mesa, AZ 85206

Correspondence

Ken Coelho, A.T. Still University, College of Graduate Health Studies, Mesa-Arizona.

Email: Ken Coelho at kcoelho@atsu.edu Or Catherine Belden at cbelden@atsu.edu.

History

- Submission Date: 20-02-2016;

- Review completed: 12-03-2016;

- Accepted Date: 23-04-2016.

DOI : 10.5530/ijmedph.2016.2.3

Article Available online http://www.ijmedph.org/v6/i2

\section{Copyright}

(c) 2016 Phcog.Net. This is an open-access article distributed under the terms of the Creative Commons Attribution 4.0 International license.

\begin{abstract}
The purpose of this systematic review is firstly to critically appraise and summarize the peerreviewed published evidence on the relationship between the caste system and risk factors for poor health status in India and secondly, to discuss the concept of the social gradient and policies that have been developed to address social inequalities of healthcare in India. Studies explored the relationship between caste membership and health-related risk factors such as mortality, health behaviors, and nutritional status. Review revealed odds of mortality; poor health behaviors and poor nutritional status were higher and in some cases were significantly higher in lower caste groups in comparison to reference groups. Odds ratios reported for mortality and poor health behaviors were significantly higher in older populations. Odds ratios reported for nutritional status and mortality were significantly higher in younger populations. Further research on the independent effects of wealth and education would broaden the scope of the social gradient health equation in India.
\end{abstract}

Key words: Caste system, Health-related risk factors, Smoking, Tobacco, Mortality, Nutrition, India.

\section{INTRODUCTION}

Evidence from existing literature suggests that social circumstances dictate underlying health outcomes. The Black report triggered studies in industrialized countries to examine social factors underlying health outcomes. ${ }^{8}$ Differences in mortality and life expectancy contribute to what is commonly referred to as the social gradient; i.e., one's chances of death are higher the lower one is on the social ladder. ${ }^{13}$ Sir Michael Marmot demonstrated this in his pivotal study on British civil servants and as Chair of the World Health Organization (WHO) Committee on the Social Determinants of Health argued that the social gradient to health depends on more than just risk factors; ${ }^{11}$ it is also dependant on social and environmental factors. For example, in the United States., members of a racial or ethnic minority group are more likely to experience differences in access to insurance coverage and health services, health behavior, and living conditions. ${ }^{16}$

Examination of these risk factors for diseases under varying social environments would serve useful in addressing and targeting social health policy. In a heterogeneous country such as India, social status is defined by the caste system, social groupings of historical and social significance representing social status and reflecting the unequal and unjust distribution of resources. ${ }^{10}$ One would argue that simply measuring the distribution of health status across the population by using metrics such as life expectancy and mortality associated with equality indicators, such as economic status, would suffice; ${ }^{23}$ however, this neglects the historical social criteria, disregarding health inequalities.

Thus, the objective of this paper is to review the literature on the relationship between caste membership and health-related risk factors in India based on developed inclusion and exclusion criteria. Inclusion criteria is based on caste membership in one of the key defined caste groups and key word search terms include physiological and behavioural risk factors for health status such as mortality, nutritional status and health behaviours such as smoking and dietary factors. The purpose of this systematic review is twofold: firstly, to critically appraise and summarize the peer-reviewed published evidence on the relationship between the caste system and risk factors for poor health status in India and secondly, to discuss the concept of the social gradient and policies that have been developed to address social inequalities of healthcare in India.

The WHO Commission on the Social Determinants ing improving conditions of daily life, addressing the unequal distribution of power, money, and resources, and improving physical and mental growth in underprivileged children. ${ }^{9}$ The relevance of Health recommends principles for action includ-

Cite this article: Coelho KR, Belden C. A Systematic Review of the Literature on the Relationship between Caste Membership and Health-Related Risk Factors in India. Int. J. Med. Public Health, 2016; 6(2):61-68. 
of this review will serve audiences such as healthcare academics, health policy leaders, health advocates in the community, public health, or healthcare professionals, and government officials in India as well as countries with a large proportion of the population from the Indian diaspora, with a view to influencing and affecting the health policy dialogue both locally and globally.

\section{CASTE SYSTEM IN INDIA}

The caste system continues to play a major role in Indian society. The system, generally identified with Hinduism, is also present in other religions in the country. ${ }^{12}$ While some would argue that urban areas of the country have done away with the caste system, rural areas still ascribe to it. ${ }^{2}$ While India's constitution requires treating all individual's equally, caste-related inequalities persist. Even though caste basedreservations exist as policy in educational institutions and employment organizations, caste based healthcare inequalities are largely neglected.

\section{MEASUREMENT OF CASTE IN THE NFHS}

Population-based studies assessing the effect of caste on mortality and health status in India have been conducted largely using data from the National Family Health Survey (NFHS), a nationally representative large-scale, multi-round survey conducted in households throughout the country. ${ }^{24,25}$ NFHS funded by the USAID and UNICEF, was conducted in 1992, 1998, and 2005. NFHS measured caste membership as a dichotomous variable - whether or not a household belonged to a lower caste (designated as Scheduled caste, Scheduled Tribe or Other Backward Classes) as detailed in the Government of India Schedule of lower castes, using self-report of the head of the household..$^{24,25}$

\section{METHODS}

\section{Literature Search}

A systematic review of the literature used PubMed to conduct the search. A search in the first database was conducted by searching for Medical Subject Heading (MeSH) keywords "caste system" OR "Scheduled Tribe" OR "Scheduled Caste" OR "Other backward class" AND "Health-related risk factors" OR "Mortality" OR "Morbidity" OR "Health Behaviour" OR "Health Behaviours" OR "Risk Factor" OR "Nutrition" OR "Nutritional status". This was then limited to papers published in English, in peer-reviewed journals in Western Countries or the Indian subcontinent.

Figure 1 summarizes the literature search, showing the search results. The titles and abstracts of these papers were scanned, and relevant outputs from this database merged resulting in 51 articles. Finally, full copies of the articles obtained and read; final sections cross-referenced with stricter study criteria brought down the number of studies used in this investigation.

\section{Inclusion criteria for literature search}

Classification of Castes: For the purpose of this review, studies examined were limited to those, which identified population groupings that have historical as well as social significance using the caste system.

Classification of Health-Related Risk Factors: Reviewed studies revealed a pattern of health- related risk factors under three major areas namely: nutritional deficiencies (vitamin A, low Body Mass Index and Anaemia); health behaviours (smoking, chewing tobacco, alcohol) and infant and adult mortality.

Information extracted from each paper includes names of the author, year of publication, states if mentioned, period, sample size, age groups, caste membership, definition, and measurement of health-related risk

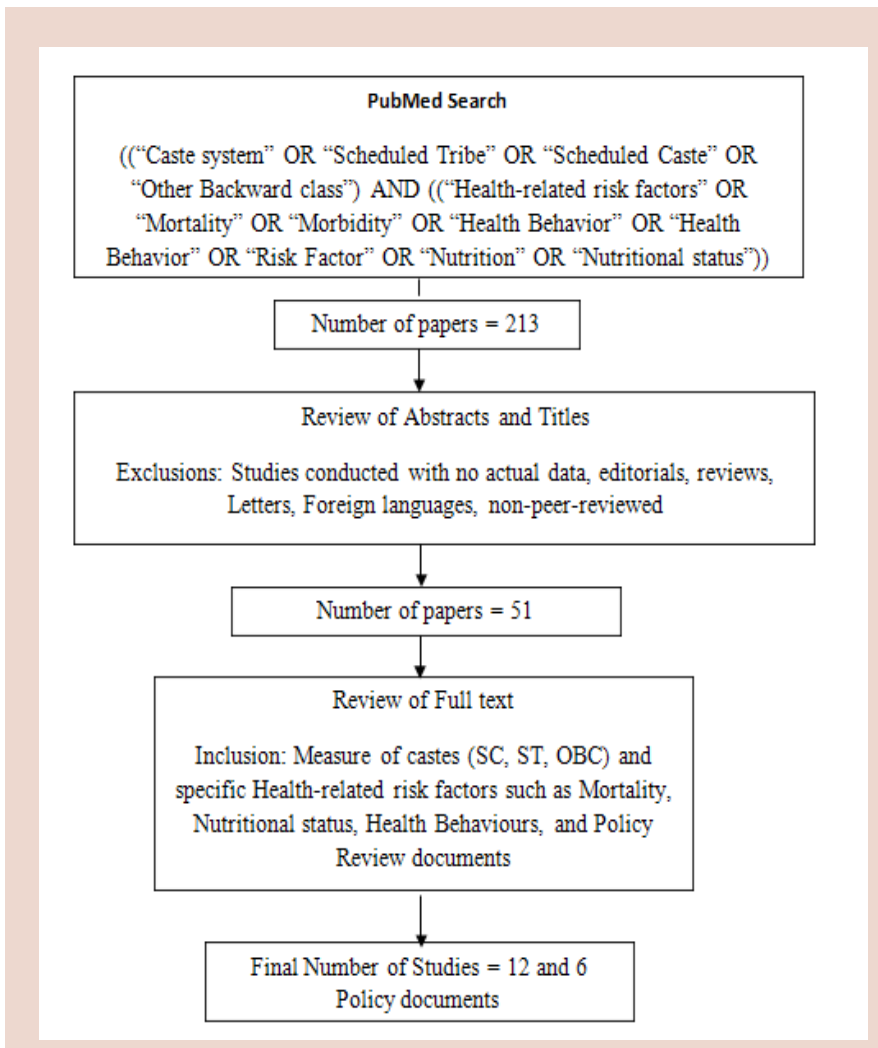

Figure 1: Literature Search Schematic

factors such as nutritional status, incidence, and prevalence of anaemia, health behaviours such as smoking, chewing tobacco and mortality, odds ratios and levels of adjustmentsused in the studies. Tables 1-7 summarize the main characteristics of the selected studies, as well as the related relevant results as described in the analysis section.

\section{RESULTS}

The literature search resulted in 12 papers and six policy documents. In all reported studies, low caste, was based on the head of household's self-identification as belonging to a scheduled caste, scheduled tribe, or other backward class. Although there is a substantial degree of heterogeneity within each category, these categories are used for population based monitoring in India. Scheduled tribes and scheduled castes are the most socially disadvantaged groups identified by the Indian government as needing affirmative action.

Mortality accessed in three studies reported odd ratios (OR) varying from 1.08 to $1.94 .{ }^{19,22,12}$ Po and Subramanian (2011) reported significantly higher odds of mortality in Other Backward Classes (OBC), Scheduled Castes (SC), and Scheduled Tribes (ST). ${ }^{19}$ However, after adjusting for wealth factors such as income, assets, and consumption per capita, the associations were no longer statistically significant with the exception of Scheduled Castes $(\mathrm{OR}=1.72$, 95\% CI $=1.23-2.41)$. Adjusting the effect of caste on mortality with household income and asset ownership independently also resulted in the attenuation of caste effect on mortality except in Scheduled Castes as mentioned above. Caste differentials in mortality were reported (Figure 2); Children and adolescents belonging to scheduled tribes had the greatest risk of mortality $(\mathrm{OR}=1.94,95 \% \mathrm{CI}=1.47-2.57)$, followed by children from scheduled castes $(\mathrm{OR}=1.35,95 \% \mathrm{CI}=1.05,1.74)$ and other backward 
classes $(\mathrm{OR}=1.33,95 \% \mathrm{CI}=1.05-1.67)$, with "other castes" as the reference group. ${ }^{22,12}$ Caste differentials in mortality were also observed in the elderly population ( $>65$ years).$^{22}$

Health-related risk behaviours (i.e. smoking tobacco, chewing tobacco and drinking alcohol) were assessed in four studies ${ }^{24,25,26,23}$ with odds ratios varying from 1.00-11.39. Caste differentials were also reported in smoking with the odds being highest for Scheduled Tribes-ST (OR $187=2.51,95 \%$ CI $=1.89-2.45)$, followed by Scheduled CastesST $(\mathrm{OR}=1.78,95$ CI- 1.61-1.96) and Other Backward Classes-OBC $(\mathrm{OR}=1.25,95 \% \mathrm{CI}=1.14-1.38)(24 ; 25)$. Similar caste differentials were also reported in drinking alcohol, with the odds ratios being highest for ST $(\mathrm{OR}=11.39,95 \% \mathrm{CI}=9.42-13.78)$, $\mathrm{SC}(\mathrm{OR}=4.47,95 \%$ CI 3.78-5.28), and $\mathrm{OBC}(\mathrm{OR}=1.9,95 \% \mathrm{CI}=1.61-2.21)$. As with smoking and drinking, a strong caste gradient was found for chewing with the odds lowest for the OBC $(\mathrm{OR}=1.24,95 \% \mathrm{CI}=1.14-1.34)$, SC $(\mathrm{OR}=1.63,95 \% \mathrm{CI}=1.49-1.78)$ and being highest for ST $(\mathrm{OR}=1.80$, $95 \% \mathrm{CI}=1.61-2.01)(24 ; 25 ; 26 ; 23)$. In three studies reported similar caste differentials across smoking and chewing tobacco separately, and combined. Odds ratios were the highest in ST, for both smoking $(\mathrm{OR}=1.27,95 \% \mathrm{CI}=1.20-1.33)$, and smoking combined with chewing $(\mathrm{OR}=1.23,95 \% \mathrm{CI}=1.18-1.29)$, followed by SC for smoking $(\mathrm{OR}=1.16$ $95 \% \mathrm{CI}=1.12-1.20)$, and chewing $(\mathrm{OR}=1.15,95 \% \mathrm{CI}=1.11-1.18)$, and combined together $(\mathrm{OR}=1.19,95 \% \mathrm{CI}=1.16-1.23))^{24,25,26,23}$

The children of Scheduled Castes and Scheduled Tribes were at a higher risk of developing anaemia $(\mathrm{OR}=2.3$ : $95 \% \mathrm{CI}=1.3-3.9)$ and Vitamin A deficiency-VAD $(\mathrm{OR}=4.5 ; 95 \% \mathrm{CI}=2.1-10.5)$ in comparison to the reference groups. Highest risk of VAD was reported (13 times higher) among children belonging to the Scheduled Caste (OR $=12.8,95 \%$ $\mathrm{CI}=5.5-29.5)$ in comparison to ST and OBC (5). Table 3 summarizes odd ratios for caste differentials in nutritional deficiencies (Anaemia and vitamin A deficiency) as reported in three studies. ${ }^{5,34}$

After adjusting for socio-economic factors in a logistical regression analysis conducted between caste and nutritional indicators of BMI and Anemia, clear caste based differentials persisted. Table 4 summarizes the state based variation in odd ratios for caste differentials in body mass index and anemia. ${ }^{21}$ State-based variation in statistically significant odds ratios for Mortalities were also reported in select age groups ${ }^{26}$ and are summarized in Table 5. Presumably, richer areas in India are likely to perform better than poorer ones, demonstrating the caste differentials in odds of child mortality by the economic status of the district in India (Figure 2).

\section{DISCUSSION}

A high range of variability in the magnitude of odds ratios among the studies were observed in this review. These observations are attributed in part to the methodological heterogeneity. The literature search identified 12 studies demonstrating increased odds of mortality, poor health behaviors and poor nutritional status among the lower caste groups (scheduled caste, scheduled tribe and other backward classes) in India.

\section{SEARCH STRATEGY AND LIMITATIONS}

It is clear that the search strategy used for this review does not come without any flaws. Only one abstracting database was used to identify all papers; PubMed database is heavily focused on North America and peer-reviewed literature in the United States. Moreover, the usage of $\mathrm{MeSH}$ key words is not always effective as it is based on the assumption that each paper is correctly assigned to the right key word terms and that the key words used in the search were reported in the abstract as well. Consequently, some studies may have been missed due to the usage of such key words. It would have been possible to repeat the search numerous times using a variety of word combinations and synonyms for the same. However, one problem with doing so would be the high number of results, most of which would not be directly related to the question of interest, and would most likely increase the likelihood of missing a relevant paper. In an ideal world, the search would have been conducted numerous times by different people to get the most accurate representation of the literature, however this was not done. Worthy of mention as a major limitation of this review is that the caste differentials in health status based on genetic factors were largely ignored. Individuals are more likely to marry people from within their caste or tribe than people from outside which means there may be significant genetic factors as well as environmental ones at play, which were not included in this review.

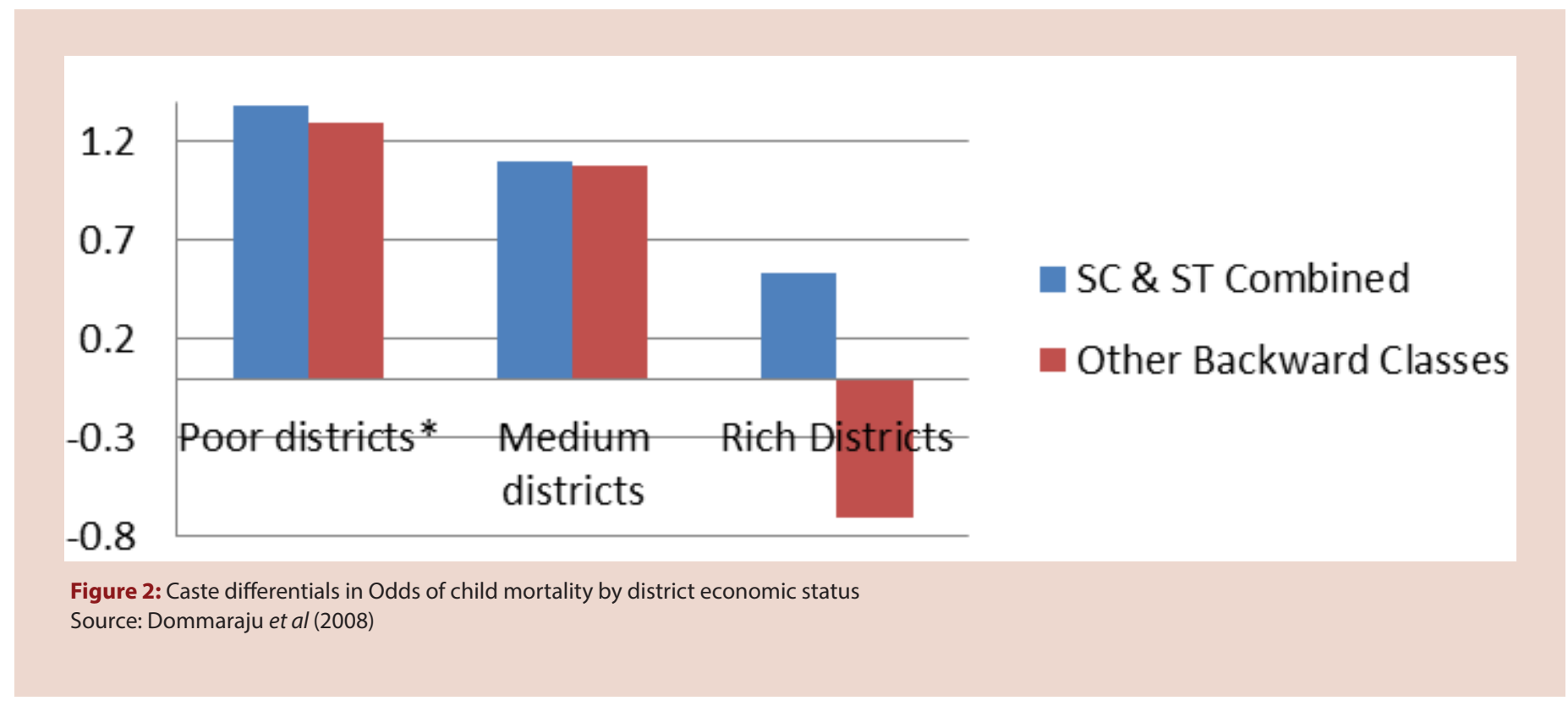




\section{LIMITATION OF CASTE AS A SOCIAL GROUPING MEASURE}

Majority of the studies (Table 1; Table 2) in this review used data from the National Family Health Survey, a large population based survey conducted nationally by the Government of India through heterogeneous regional agencies, which could partially explain the heterogeneity in results across the states within the country. Moreover, caste is measured in a rather crude manner; the heads of households required self-reporting their membership in a caste group. ${ }^{14,27}$ As with any Measure of self-report, poor validity and reliability are subject to bias the results. Underreporting and over reporting of caste membership in either lower or higher castes could lead to self-report bias and Possible misclassification. Multiple measures of caste status or membership from multiple sources/records would ensure more accuracy in classification; however in most cases it is not feasible especially considering the lack of infrastructure in some of the rural areas of the country.

As this review has demonstrated, members of low castes clearly suffer disadvantages in health. The interpretations of caste disparity, though widely acknowledged, have been criticized due to the need to focus on class instead of caste. This is based on the assumption that caste differentials have been said to arise out of class differentials. ${ }^{23}$ However, caste differentials in health status outcomes cannot be reduced to just socioeconomic differences. Congruently, this should not be taken as denying the importance of socioeconomic factors and its relationship between those factors with caste-but would be important to recognize the multidimensional aspects of caste to better understand the inequities in health and to conceive of caste and class as both mutually exclusive and Related.

\section{LIMITATIONS OF HEALTH STATUS MEASURES}

Health status measures used by all the studies in this review do not accurately capture the corollary dimensions. For example, mortality and health behavioral differentials across caste in this review were based on cross-sectional survey data, which captured only a snapshot (Table 1)

Inaccuracies in reporting age and under-reporting of deaths are possibly at play as well. For example, respondents may have reported incorrect data for dead members of the household, including age, because they remembered incorrectly.

Even though some of the nutritional indicators for health status included objective measures such as blood tests and anthropomorphic measurements, at times some individuals answer on behalf of other household members and this could have been any other possible/capable adult member. For example, in the case of assessing health behaviors, and given public attitudes regarding the acceptability of smoking and drinking, there may be reporting biases in this regard. In general, the bias is likely to be towards under-reporting, especially by younger participants and women.

\section{SOCIAL GRADIENT TO HEALTH INEQUALITIES}

The social gradient to health has been consistently observed in the developed world and is becoming increasingly important in the developing world as well as low and middle-income countries. ${ }^{12,20}$ If you are rich and come from a family lineage high up on the social ladder, you are more likely to have better access to resources, goods and improved health services. Along the same lines, people second from the bottom have worse health than those above them, but better health than those below them. ${ }^{23}$ What this means is, that in the social gradient, just focusing on those at the bottom will not be sufficient to fill the gap in equity, however a focus on the larger composite dimensions of the problem must be dissected. ${ }^{1}$ Along these lines economic, wealth factors, education, and gender are increasingly becoming more and more important as the distance between castes is becoming smaller and more dynamic. ${ }^{7}$

\section{WELFARE POLICIES IN INDIA}

Welfare and health policies have attempted to dress social disparities by focusing on constitutional, political, economic, and social agendas since the independence of India in 1947. The Government of India has also enacted affirmative action policies addressing the concerns of equality based, both, on need and merit. After the liberalization and initiation of structural reforms in India in 1993, there has no doubt been a greater understanding of inequalities in health and their social context. ${ }^{18}$ Despite a promising performance on macroeconomic variables, the slow rate of reduction in poverty, the low quality of employment generation, growing rural/urban disparities, and low health indicators such as slow progress on the Millennium Development Goals with regard to infant and maternal mortality rate shave been a source of concern.$^{23}$

The Planning Commission of India has dedicated two recent five-year plans to strengthen redistribution policies to address inequalities in the society. ${ }^{17,15}$ The recent five-year plan framed by the Indian government, for instance, aimed to provide essential primary health care to reach underserved and underprivileged populations and also to devolve funds and implement decentralized planning.

Part of the problem is that the issue has been confused. Social policy and programs in India, including the public health agenda, have traditionally been driven by development priorities set by the poverty debate, with focus on the poorest and most marginalized. Welfare policies have focused on affirmative action and have aimed at initiating social programs to redistribute jobs, housing, education and health, and both have largely been mixed up and misrepresented.

Basic improvements in living standards and equitable boarding educational opportunities are needed. There is need to target programs and interventions that are simultaneously oriented to both, the poorest and most marginalized, and also across populations to address a range of socioeconomic measures in Indian society. Therefore, the full implications of the social gradient and its role in mediating relationships between economic development and health in India still needs to be fully reflected in the changes and choices made in health policies.

\section{CONCLUSION}

As one would intuitively suspect, this review demonstrates a clear association between lower caste membership and increased odds of mortality, poor health behaviors and poor nutritional status. This is indicative of substantial social inequalities in health status due to caste membership.However, these results can also be attributed to sample selection biases in case ascertainment and not adequately accounting for confounding factors such as education and wealth in the community. Future reviews should include studies on body mass index or height between castes. Due to the lack of a conceptual framework for how social caste may be interpreted in light of the many gradations of the caste system in India, as well as the numerous sub-castes, research on the social inequalities of healthcare in India must focus on the evaluation of relative strengths in both the economic and social status factors of populations in varying geographic locations within the country to best determine variations in the overall status of health outcomes. In addition, there is a great need for improved methodological dimensions and data availability to build wider evidence across the social gradient. The goal is to shape policies oriented toward addressing society and health, in particular inequalities. There is a need not only for national level studies such as the ones discussed in this review but also for comparative research across rural and urban areas, states, and districts to enable the mapping of these dimensions with much greater accuracy. 


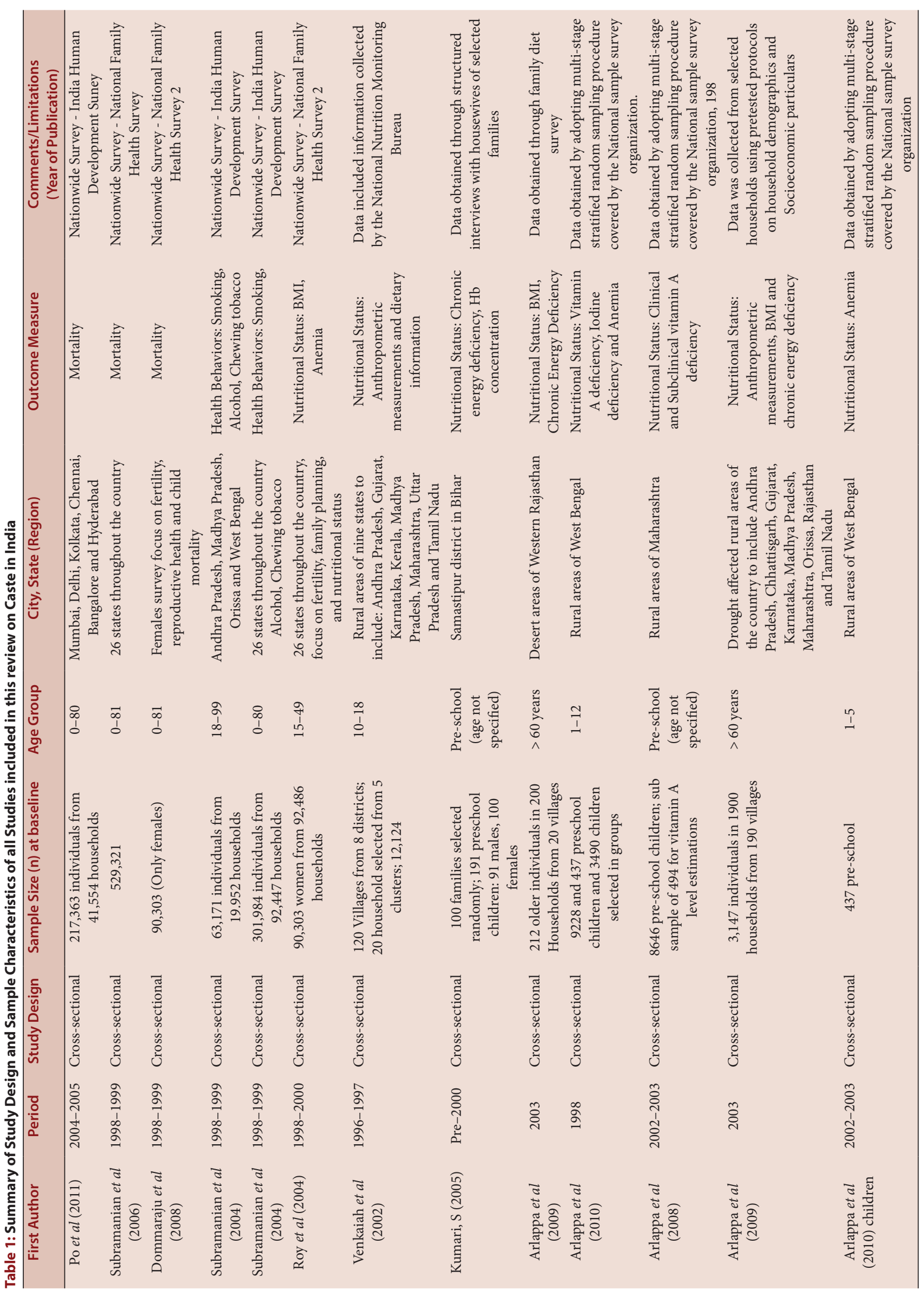



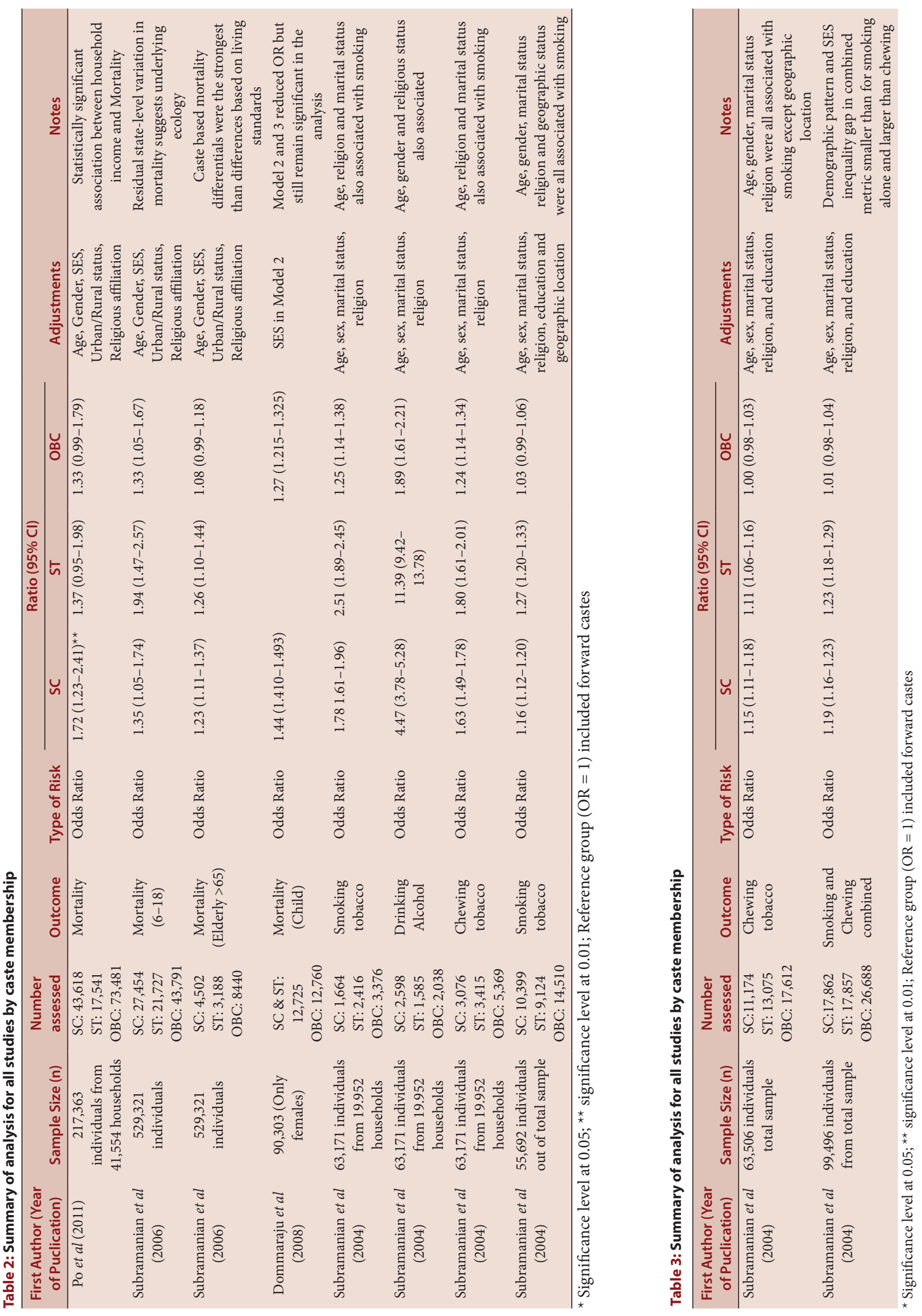

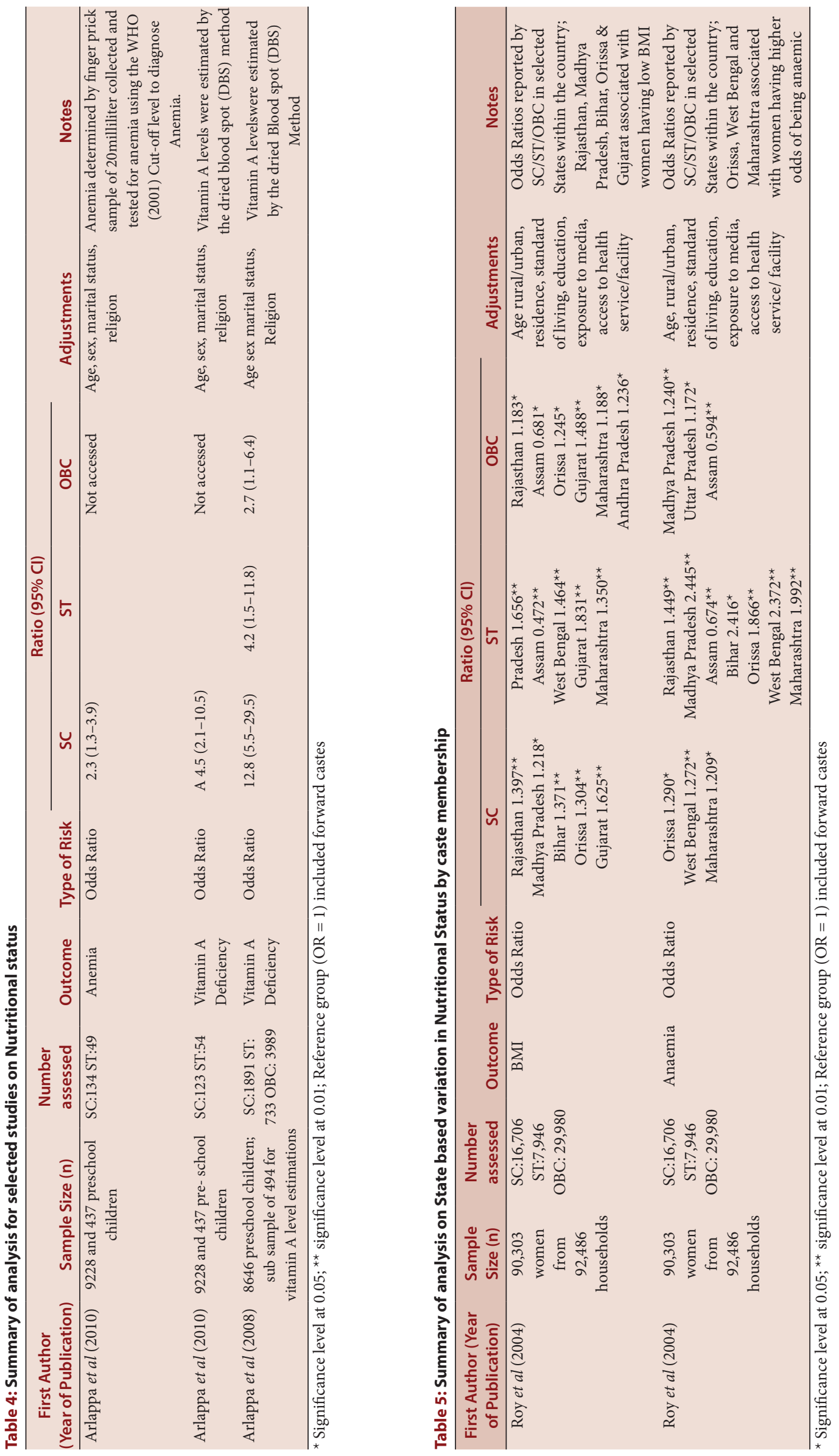
Table 6: Statistically Significant Adjusted Odds Ratio's for Mortality Risk Associated with State of Residence; (By selected age group)

\begin{tabular}{cccc}
\hline State & $<1$ year (Infants) & State & $>65$ years (Elderly) \\
\hline Kerala & 0.53 & Nagaland & 0.72 \\
West Bengal & 0.65 & Karnataka & 0.8 \\
Tamil Nadu & 0.72 & Kerala & 0.73 \\
Karnataka & 0.74 & Madhya Pradesh & 0.86 \\
Meghalaya & 1.56 & Rajasthan & 1.24 \\
Madhya Pradesh & 1.58 & West Bengal & 1.28 \\
Haryana & 2.14 & Andhra Pradesh & 1.32 \\
Rajasthan & 2.14 & Bihar & 1.57 \\
\hline
\end{tabular}

Source: Indian National Family Health Survey (1998-1999).

Table 7: Reported Association Studies - Lower Caste and Nutritional Deficiencies - Vitamin A, BMI \& Anemia

\begin{tabular}{ccccc}
\hline & SC $n(\%)$ & ST $n(\%)$ & OBC $n(\%)$ & $\mathrm{p}^{\prime \prime}$ value* \\
\hline Vitamin A Deficiency & $103(52)$ & $32(88)$ & $246(52)$ & $<0.01$ \\
Arlappa et al (2008) & \multicolumn{1}{c}{$1330(57)$ X } & 1817 & $<0.001$ \\
BMI Arlappa et al (2009) & combined score & $(44.2)$ & \\
Anaemia Arlappa et al (2010) & $134(82.8)$ & $49(100)$ & & $<0.01$
\end{tabular}

${ }^{\star}$ Significance accessed at $\mathrm{p}<0.05$

\section{REFERENCES}

1. Adler NE, Epel ES, Castellazzo G, Ickovics JR. Relationship of subjective and objective social status with psychological and physiological functioning: preliminary data in healthy white women. Health psychology: official journal of the Division of Health Psychology, American Psychological Association. 2000;19(6):586.

2. Arlappa N, Balakrishna N, Brahmam GN, Vijayaraghavan K. Nutritional status of the tribal elderly in India. Journal of nutrition for the elderly. 2005;25(2):23.

3. Arlappa N, Balakrishna N, Laxmaiah A, Brahmam GN. Prevalence of anaemia among rural pre-school children of West Bengal, India. Annals of human biology. 2010;37(2):231.

4. Arlappa N, Laxmaiah A, Balakrishna N, Harikumar R, Kodavanti MR, Gal RC, Saradkumar S, Ravindranath M, Brahmam GN. Micronutrient deficiency disorders among the rural children of West Bengal, India. Annals of human biology. $2011 ; 38(3): 281$.

5. Arlappa N, Rao KM, Venkaiah K, Brahmam GN, Vijayaraghavan K. Nutritional parameters and chronic energy deficiency in older adults of desert areas of western Rajasthan, India. Journal of nutrition for the elderly. 2009;28(1):61.

6. Arlappa N, Venkaiah K, Rao KM, Reddy C, Kumar SS, Ravindranath M, Brahmam GN, Vijayaraghavan K. Prevalence of chronic energy deficiency in rural-dwelling older Indian adults during a period of severe drought. Journal of nutrition for the elderly. 2009;349 28(3):301.

7. Balarajan Y, Selvaraj S, Subramanian SV. Health care and equity in India. Lancet. 2011;377(9764):505.
8. Black D, Morris J, Smith C, Townsend P. Inequalities in health: report of a Research Working Group. London: Department of Health and Social Security. 1980 Aug;19.

9. Blas E, Gilson L, Kelly MP, Labonté R, Lapitan J, Muntaner C, Ostlin P, Popay J, Sadana R, Sen G, Schrecker T. Addressing social determinants of health inequities: what can the state and civil society do?. Lancet (London, England). 2008;372(9650):1684.

10. Borooah V. Inequality in health outcomes in India: the role of caste and religion. University Library of Munich, Germany; 2010;:179-207.

11. Brunner EJ, Marmot MG. Social organisation, stress and health. In: Marmot MG and Wilkinson, R and G (eds.), Social Determinants of Health (pp. 17-43). Oxford University Press, Oxford; 2005; 17-43.

12. Dommaraju P, Agadjanian $\mathrm{V}$, Yabiku S. The Pervasive and Persistent Influence of Caste on Child Mortality in India. Popul Res Policy Rev. 2008;27(4):477-195.

13. Epstein H. Life and death on the social ladder (Inequality, life expectancy and stress). New York Review of Books. 1998;45(12):26-30.

14. International Institute for Population Sciences (IIPS) and ORC Macro. 2000 National Family Health Survey (NFHS-2), 1998-99: India. Mumbai: IIPS. Retrieved from http://www.measuredhs.com/pubs/pdf/FRIND2/FRIND2.pdf .

15. Kumari S. Nutritional status of scheduled caste pre-school children. Indian journal of public health. 2005;49(4):258-9.

16. Lillie-Blanton M, Brodie M, Rowland D, Altman D, Mclntosh M. Race, ethnicity, and the health care system: public perceptions and experiences. Medical Care Research and Review.2000;57(4 suppl):218-35.

17. Luke N. Munshi K. Social Affiliation and the Demand for Health Services: Caste and Child Health in South India. Journal of development economics. 2007;83(2):256.

18. Irving M, Smith G, Gordon D, Nandy S, Subramanian SV. Poverty, child under nutrition and morbidity: new evidence from India. Bulletin of the World Health Organization. 2005;83(3):210.

19. Po JY, Subramanian SV. Mortality Burden and Socioeconomic Status in India. PLoS ONE.2011;6(2): e16844.

20. Rao, M. Tackling health inequalities in India. Perspectives in Public Health. 2009;129(5):205-6.

21. Roy TK, Kulkarni S, Vaidehi Y. Social inequalities in health and nutrition in selected states.Economic and Political Weekly. 2004'14:677-83.

22. Srinivasan K, Mohanty SK. Deprivation of basic amenities by caste and religion. Empirical study using NFHS data. Economic and Political Weekly. 2004;14: 728-35.

23. Subramanian SV, Ackerson LK, Subramanyam M, Sivaramakrishnan K. Health inequalities in India: the axes of stratification. Brown J. World Aff. 2008; $14: 127$.

24. Subramanian SV, Nandy S, Kelly M, Gordon D, Smith GD. Patterns and distribution of tobacco consumption in India: cross sectional multilevel evidence from the 1998-9 national family health survey. BMJ. 2004;328(7443):801-6.

25. Subramanian SV, Nandy S, Kelly M, Gordon D, Smith GD. Health behaviour in context: exploratory multi-level analysis of smoking, drinking and tobacco chewing in four states. Economic and Political Weekly. 200414:684-93.

26. Subramanian SV, Nandy S, Irving M, Gordon D, Lambert H, Smith GD. The Mortality Divide in India: The Differential Contributions of Gender, Caste, and Standard of Living Across the Life Course. American Journal of Public Health. 2006;96(5):818.

27. Venkaiah K, Damayanti K, Nayak MU, Vijayaraghavan K. Original Communication Diet and nutritional status of rural adolescents in India. European Journal of Clinical Nutrition. 2002;56:1119-25. 